\title{
Análise da competitividade das exportações brasileiras de mel natural, segundo o modelo constant market share e o índice de vantagem comparativa revelada
}

\author{
Maristela Franchetti de Paula ${ }^{*}$, Anadalvo Juazeiro dos Santos ${ }^{2}$, Romano Timofeiczyk Junior ${ }^{2}$, Vitor Afonso \\ Hoeflich ${ }^{2}$, João Carlos Garzel Leodoro da Silva², Humberto Angelo ${ }^{3}$
}

10.1590/0034-737X201663050004

\section{RESUMO}

O objetivo deste estudo foi analisar os indicadores de competitividade no comércio exterior do produto mel natural, entre 2000 e 2011. Em 2000, o Brasil iniciou a inserção desse produto no mercado internacional, ganhando rápida projeção como país exportador. No entanto, ainda ocupa posição intermediária entre os principais exportadores mundiais. O problema analisado neste estudo está relacionado com a competitividade desse produto, no mercado, a partir de indicadores econômicos. Os procedimentos metodológicos utilizados para verificar a competitividade foram o modelo constant market share e o índice de vantagem comparativa revelada (IVCR). Constatou-se que o quantum e o valor exportado apresentam tendência de crescimento e de flutuações no mercado internacional. No período estudado, a China e a Argentina destacavam-se como os principais exportadores mundiais de mel natural e o Brasil era o sétimo maior exportador. Conclui-se que o País apresenta competitividade no mercado externo de mel natural e padrões de eficiência e de utilização de recursos semelhantes aos vigentes no mundo, além de potencial para ampliar sua participação, com um produto competitivo e diferenciado.

Palavras-chave: mel natural; competitividade; constant market share.

\section{ABSTRACT}

\section{Analysis of the competitiveness of Brazilian exports of natural honey, according to the constant market share model and the revealed comparative advantage index}

The objective of this paper is to analyze the indicators of competitiveness in foreign trade of natural honey product between the years 2000-2011. Brazil, from 2000, initiated the insertion of this product in the international market, gaining rapid recognition as the exporting country, however, still occupies an intermediate position between the world's major exporters. The problem to be studied is the competitiveness this product in the international market from economic indicators. The methodological procedures used to verify the competitiveness abroad are the Constant Market Share Model and Index of Revealed Comparative Advantage (IVCR). It was observed that the quantum and export value have a tendency of growth and fluctuations in the international market. The main exporters are China and Argentina, Brazil is the seventh exporter in the study period. We conclude that Brazil has competitiveness in foreign markets natural honey and standards of efficiency and use of resources similar to those prevailing in the world, and has the potential to increase its share, with a competitive and differentiated product.

Key words: natural honey; competitiveness; constant market share.

Recebido em 25/05/2014 e aprovado em 17/10/2016

${ }^{1}$ Universidade Estadual do Centro-Oeste, Departamento de Administração, Guarapuava, Paraná, Brasil. maristela.ufpr@gmail.com

${ }^{2}$ Universidade Federal do Paraná, Departamento de Economia Rural e Extensão, Curitiba, Paraná, Brasil. ajsantos@ ufpr.br; romano.timo@gmail.com; vitor.ufpr@gmail.com; garzel@ufpr.br

3 Universidade de Brasília, Brasília, Distrito Federal, Brasil. hum@unb.br

*Autora para correspondência: maristela.ufpr@gmail.com

Rev. Ceres, Viçosa, v. 63, n.5, p. 614-620, set/out, 2016 


\section{INTRODUÇÃO}

A relevância da apicultura está no fato de ela ser uma atividade agropecuária que atende aos requisitos dos três pés da sustentabilidade: o econômico, o social e o ecológico. O econômico é o gerador de renda para os produtores; o social intensifica a ocupação de mão de obra familiar no campo, com diminuição do êxodo rural; e o ecológico refere-se à polinização de espécies nativas e cultivadas e à conservação da vegetação, uma vez que não é necessário desmatar para criar abelhas (Sommer, 1998).

Além de ser uma importante atividade agropecuária que gera renda complementar para os pequenos e médios proprietários rurais, a apicultura oferece vantagens como demandar baixo volume de investimento, não exigir dedicação exclusiva, assegurar a diversificação da produção na propriedade e apresentar a possibilidade de produção durante o ano todo, graças ao clima e à flora (Paula, 2008).

Outra vantagem da apicultura brasileira, reconhecida internacionalmente, é que a abelha africanizada não recebe qualquer tratamento sanitário em suas colmeias, estando $80 \%$ delas instaladas em floras nativas; portanto, em condição de oferecer produtos apícolas orgânicos aos mercados interno e externo.

Em contrapartida, uma das barreiras para a expansão da produção do mel natural no Brasil é o baixo consumo, que está associado ao baixo nível de renda e à falta de hábito de consumo, no País, como também à visão de que o mel é um produto somente medicinal e ao desconhecimento de suas características nutricionais (Zandonadi \& Silva, 2005).

O consumo de mel no Brasil é um dos mais baixos do mundo, não ultrapassando a média de $120 \mathrm{~g}^{\mathrm{ano}}{ }^{-1}$ por habitante. Praticamente, é o mesmo consumo da Argentina, da China e do Uruguai, volume que contrasta com os $3,4 \mathrm{~kg} \mathrm{ano}^{-1}$ da República Centro-Africana; $1,8 \mathrm{~kg} \mathrm{ano}^{-1} \mathrm{da}$ Nova Zelândia; $1,7 \mathrm{~kg}$ ano $^{-1}$ da Angola; $1,5 \mathrm{~kg}^{\mathrm{ano}}{ }^{-1} \mathrm{da}$ Grécia; $1,4 \mathrm{~kg}$ ano $^{-1}$ da Áustria; $1,3 \mathrm{~kg}$ ano $^{-1}$ da Suíça; 1,2 $\mathrm{kg} \mathrm{ano}^{-1}$ da União Europeia; $1,1 \mathrm{~kg}^{-1} \mathrm{ano}^{-1}$ da Alemanha, 847 $\mathrm{g}$ ano $^{-1}$ da Espanha, $576 \mathrm{~g}^{-1} \mathrm{ano}^{-1}$ dos Estados Unidos da América e $310 \mathrm{~g} \mathrm{ano}^{-1}$ do México (Sebrae, 2009).

Sebrae (2009) também aponta outras dificuldades para a produção de mel no País: o pequeno apicultor, em muitos casos, não tem condições de transportar quantidades grandes de mel e também tem dificuldades de armazenamento, além de necessitar de terceiros para certificar, revender ou exportar seu produto. Consequentemente, parte da produção é destinada ao intermediário, que adquire o mel em grande quantidade para revenda ao varejo ou para exportação, ficando com a maior margem de lucro.

Souza (2006) ressalta que existem problemas técnicos e que as melhorias devem acontecer em diversas áreas espe- cíficas da atividade, estando entre as principais aquelas que tratam do manejo, do controle da qualidade, do aumento da produtividade, da gestão da produção, dos mecanismos de financiamentos, da capacitação dos apicultores e das estratégias de política e promoção comercial.

O novo Regulamento da Inspeção Industrial e Sanitária de Produtos de Origem Animal (Riispoa) é considerado um dos principais entraves para os apicultores brasileiros. De acordo com a Abemel (2013), a principal crítica ao regulamento é em relação à obrigatoriedade de registro no serviço de inspeção federal ou em uma instância equivalente da unidade de extração de produtos das abelhas (Uepa), também conhecida como "casa de mel”. Segundo a associação de produtores, além do custo inicial de mais de $\mathrm{R} \$ 60$ mil para as instalações, o novo regulamento deve gerar gastos mensais superiores a $\mathrm{R} \$ 2.000,00$. Os produtores afirmam que esses valores são inviáveis, uma vez que as casas de mel são usadas somente durante dois ou três meses por ano, por causa da sazonalidade do produto.

Todos esses fatores resultam em baixa produtividade dos apiários brasileiros. Segundo a Abemel (2013), estima-se que o Brasil explora apenas $15 \%$ do potencial da flora apícola e que cerca de 350 mil apicultores participam desse setor, dos quais $90 \%$ praticam a agricultura familiar, com renda média anual de $\mathrm{R} \$ 6$ mil.

É importante ressaltar que a produção nacional $(\mathrm{kg})$ aumentou consideravelmente no período estudado, compara-se com o crescimento dos anos anteriores. Esse crescimento deve-se à oportunidade que se abriu no mercado -internacional, por causa das restrições que foram impostas à China e à Argentina, entre 2001 e 2003. Em 2004, esses países voltaram ao mercado, mas o Brasil não retornou aos patamares anteriores de produção.

As regiões que mais contribuíram para elevar a produção foram as sudeste e sul, apesar do avanço da produção das regiões norte, nordeste e centro-oeste. Conforme o IBGE (2012), praticamente todos os estados do Brasil produzem mel natural, sendo os maiores produtores Rio Grande do Sul, Paraná, Santa Catarina, Piauí, Minas Gerais, Ceará, São Paulo e Bahia.

Mesmo com o avanço do setor apícola, a participação do Brasil na produção mundial ainda é baixa. Atualmente, 139 países desenvolvem atividades apícolas, destacando-se na produção de mel natural, em ordem decrescente, China, com 26,4\% da produção mundial, Turquia com 5,8\%, Ucrânia com 4,3\%, Estados Unidos com 4,1\%, Índia e Rússia com 3,7\%, cada, Argentina com 3,6\%, México com 3,5\%, Etiópia com 3,3\% e Irã com 2,9\%. Em 2000, o Brasil participou com 1,7\%, em 2005 com 2,37\% e em 2011 com $2,5 \%$ do total de mel natural produzido, ocupando o $11^{\circ}$ lugar no ranking mundial. Esse bloco de países produz mais de $60 \%$ do volume mundial de mel natural (FAO, 2013). 
Embora tenha apresentado esse crescimento, o Brasil produziu 41,5 toneladas de mel em 2011, enquanto a produção mundial foi de 1,6 milhão, O principal fator da baixa participação é a produção por colmeia, que é de 15 a $20 \mathrm{~kg}$ ano $^{-1}$, considerada abaixo da média de outros países, como a Argentina, que produz 35 a $40 \mathrm{~kg} \mathrm{ano}^{-1}$; o México, com produção de $25 \mathrm{~kg}^{\mathrm{ano}}{ }^{-1}$; e a China, com até $50 \mathrm{~kg}^{\mathrm{ano}}{ }^{-1}$ por colmeia.

Um dos fatores que contribuíram para a expansão do setor apícola foi o mercado internacional. Entre 2000 e 2011, as exportações de mel natural no mundo atingiram cerca de 4,8 milhões de toneladas e um valor real aproximado de US\$12,5 bilhões. As exportações mundiais de mel natural apresentaram oscilações, mas no período de 2000 a 2011, houve tendências crescentes, tanto em quantidade como em valor. As flutuações são atribuídas aos embargos, aos fatores climáticos, ao aumento do número de colmeias e da produção por colônia, ao interesse por produtos naturais e ao maior consumo do mel natural durante os últimos anos (Zandonadi \& Silva, 2006).

Destaca-se a redução da quantidade exportada no mercado mundial de mel natural entre 2002 e 2004, resultante das restrições impostas à China e à Argentina, pela Europa e pelos Estados Unidos. A decisão da Comunidade Europeia de suspender as importações de mel chinês foi devida aos altos índices de resíduos de drogas veterinárias encontrados em seu produto. Concomitantemente, os Estados Unidos também suspenderam as importações de mel da Argentina, alegando distorções no preço do produto, o que promovia concorrência desleal com os próprios produtores americanos, tomando essa decisão como medida antidumping (Sebrae, 2006).

Nessa fase, o mercado mundial de mel atravessou um período com problemas de oferta, principalmente por causa da redução temporária das exportações desses dois países com tradição exportadora, cenário favorável à entrada de países produtores com baixa participação no mercado internacional, como o Brasil.

Em 2005, com o término das restrições, ocorreu a retomada do crescimento das exportações mundiais, que foram posteriormente reduzidas em 2008. Esse evento decorreu da crise econômica global iniciada naquele ano; da quebra de safra na China, na Argentina e no Vietnam, em razão de problemas climáticos, e da aplicação de medidas antidumping contra a China, pelos Estados Unidos (Paula, 2008).

A partir de 2009, o mercado internacional de mel apresentou certa estabilidade, pois os grandes exportadores mundiais tiveram a mesma taxa média de crescimento e os preços estavam dentro de uma média mundial, com exceção da China, que praticou um preço bem abaixo da média dos outros países.
O Brasil intensificou sua participação no mercado externo a partir dos embargos impostos à China e à Argentina, em 2001. O País passou a ser um dos maiores exportadores mundiais em um curto espaço de tempo, por suas características sociais, econômicas e ambientais, que possibilitaram o desenvolvimento da produção apícola.

Por essas razões, as exportações brasileiras deram um salto vertiginoso, passando de pouco mais de 260 toneladas exportadas, em 2000, para mais de 12,5 mil toneladas, em 2002. O Brasil expandiu suas exportações durante aproximadamente três anos, período em que o mercado ressentia-se dos problemas com a China e a Argentina. A evolução brasileira no setor foi interrompida com o fim dos embargos impostos, e com o reequilíbrio do mercado, o preço médio recebido pelos brasileiros diminuiu, fato observado a partir de 2004. Esse período foi marcado pela agressividade da China, que retornou ao mercado com preços mais baixos que a sua média, colocando o produto no mercado de forma a dificultar a competitividade, e pelo aumento das exigências em relação à qualidade do mel.

Em 2006, conforme relatou Rangel (2011), ao mesmo tempo em que uma crise sem precedentes afetava a produção de mel dos Estados Unidos e da Europa, a União Europeia decretou embargos às exportações do mel brasileiro. Esse fato fez com que a quantidade e o valor das exportações brasileiras continuassem em baixa, entre 2006 e 2007.

Inicialmente, a restrição europeia apresentou-se como um problema para as aspirações brasileiras no mercado mundial de mel, mas trouxe algumas consequências positivas. Uma delas foi chamar atenção dos empresários do setor apícola para a necessidade de fortalecimento de suas organizações setoriais. Além disso, o Brasil direcionou suas exportações para os Estados Unidos; portanto, não houve reduções de suas exportações, em relação a 2005, e ainda ampliou o seu market share com a entrada em um mercado até então pouco explorado.

O Brasil recuperou o mercado europeu em 2008, por duas razões fundamentais: a ação governamental brasileira na construção de laboratórios para o controle e o monitoramento de resíduos no mel e a pressão por parte dos países consumidores europeus, por causa da escassez do produto em seu território (Sebrae, 2009). No entanto, deve ser ressaltado que os Estados Unidos consolidou-se como principal destino do mel brasileiro, respondendo por $66 \%$ das exportações, em 2009.

Mesmo com as oscilações mencionadas, entre 2000 e 2011, o Brasil atingiu a taxa de crescimento de $648 \%$ em quantidade e de $111 \%$ em seu preço médio, nas exportações de mel natural, o que evidencia que a quantidade e o valor de exportação não seguiram a mesma tendência ao longo do período estudado. 
A participação dos principais importadores do Brasil, no período estudado, foi: Estados Unidos, 54\%; Alemanha, 29\%; Reino Unido, 9\%; Canadá, 2,5\%; Espanha, $1,3 \%$; Bélgica, $1 \%$; França e Áustria, com, aproximadamente, $0,5 \%$, cada. e outros países, com quase $2 \%$.

Os maiores importadores do mel brasileiro, ou seja, os Estados Unidos, a Alemanha e o Reino Unido, somam $92 \%$ do total das exportações. Embora pequena, mas crescente, destacou-se a participação dos demais países na demanda dessas exportações, o que evidencia a abertura de novos mercados e a possível redução da dependência dos dois principais importadores.

Os Estados Unidos, o maior importador mundial de mel natural, têm como principais fornecedores a Argentina, a China, o Vietnã e o Canadá, com 18, 16, 13,94 e 12\%, respectivamente. O Brasil participou com 8,29\% das importações de mel natural norte-americanas (Uncomtrade, 2013).

AAlemanha foi o segundo maior importador mundial de mel natural, sendo a Argentina seu principal fornecedor, com $30 \%$ de participação no total importado. Em seguida, vêm o México e o Uruguai, com 14 e $6 \%$ da importação, respectivamente, enquanto o Brasil participou com somente $4,26 \%$.

Constata-se que a importância que os Estados Unidos e a Alemanha têm para as exportações brasileiras não é a mesma que o Brasil tem nas importações desses países. Esse fato demonstra a fragilidade do País diante desses mercados, por apresentar baixa participação nas suas importações, o que, no entanto, pode ser visto como uma oportunidade de ampliação da sua participação nesses mercados.

Deve-se ressaltar que a apicultura nacional virou a página de uma história de produção incipiente e limitada ao consumo local, encontrando-se, atualmente, em um novo patamar. A expansão da participação no mercado internacional estimulou investimentos a partir de 2001, o que proporcionou a elevação da produção e a reorganização do setor, em bases mais comerciais e empresariais. Diante desse cenário, este estudo buscou analisar os indicadores de competitividade do produto mel natural no comércio exterior, no período de 2000 a 2011.

\section{MATERIAL E MÉTODOS}

Para análise da competitividade do mel natural brasileiro no mercado internacional, no período de 2000 a 2011, foram utilizados dados secundários, coletados em fontes como: United Nations Commodity Trade Statistics Database (Uncomtrade; 2013); FAO - Organização das Nações Unidas para Agricultura e Alimentação (2013), e Sistema de Análise das Informações de Comércio Exterior, Secretaria de Comércio Exterior (Alice Web; 2013).
Para o levantamento bibliográfico sobre a produção e as exportações de mel natural, foram utilizadas diversas fontes de consulta, como: Confederação Brasileira de Apicultura (CBA), Associação Brasileira de Exportadores de Mel (Abemel), Serviço Brasileiro de Apoio às Micro e Pequenas Empresas (Sebrae), entre outras entidades ligadas ao setor apícola.

Os dados das séries temporais anuais, de 2000 a 2011, do produto mel natural, coletados no banco de dados da Uncomtrade, dizem respeito ao volume ( $\mathrm{t}$ ) e ao valor (US\$) das exportações brasileiras e mundiais. Esses dados estão expressos em milhões de dólares e deflacionados para o ano de 2011, com base no índice dos Estados Unidos Consumer Price Index (CPI), por se tratar de comércio internacional.

A análise da competitividade do mel natural brasileiro no mercado internacional foi feita por meio das metodologias constant market share (CMS) e índice de vantagem comparativa revelada (IVCR).

\section{Constant Market Share (CMS)}

Modelo amplamente difundido por Richardson (1971) tem sido utilizado nos estudos sobre o crescimento e o desempenho do comércio exterior e para analisar os fatores que exercem influência nas exportações de uma nação, em um horizonte temporal.

O CMS busca avaliar os efeitos e as influências na evolução das exportações de um determinado produto em um período considerado, além de revelar o desempenho de uma firma ou um país diante dos seus principais concorrentes. Pelo CMS, o crescimento favorável ou desfavorável do setor exportador é atribuído à estrutura das exportações do país e à sua competitividade. A principal vantagem desse método é permitir a análise por componentes e pelo comportamento do produto no mercado de destino (Valverde et al., 2006).

No método CMS, as variações da participação no mercado mundial podem ser descompostas em fontes de crescimento das exportações e os elementos responsáveis pelo comportamento podem ser identificados. Conforme Horta (1983), esses efeitos são expressos em:

- Efeito crescimento do comércio mundial: o crescimento das exportações decorre do crescimento mundial.

- Efeito destino das exportações: representa os ganhos ou as perdas em termos da taxa de crescimento, dado o fato de o país exportar para mercados que cresceram a taxas superiores ou inferiores à média observada para todos os países.

- Efeito composição da pauta: maior concentração na pauta de exportação de produtos cuja demanda mundial cresce mais rapidamente. Esse efeito permite identificar os ganhos ou as perdas em termos da taxa de crescimento, 
devidos à concentração de pauta em produtos que apresentaram taxas de crescimento mais elevadas, ou menores, que a média de todos os produtos).

- Efeito competitividade: é determinado de forma residual e reflete a diferença entre o crescimento efetivo das exportações e o que teria ocorrido nas exportações do país se a participação de cada bem tivesse sido mantida para os mercados compradores. Significa que uma economia é competitiva na produção de determinado produto quando consegue, pelo menos, se igualar aos padrões de eficiência vigentes no resto do mundo quanto à utilização de recursos e à qualidade do bem.

Segundo Ferraz et al. (1995), o CMS é o principal indicador de competitividade e é definido como sendo a participação de um produto, uma empresa ou uma nação em um determinado mercado. Ele é expresso por:

$\Sigma V^{\prime} i j-V i j=\Sigma r V j+\Sigma i \Sigma j(r i j-r i) V j+\Sigma\left(V^{\prime} j-V j-\right.$ - rj $V j)$

em que:

$V^{\prime} i j=$ valor monetário das exportações da mercadoria $i$ (mel natural) do país em foco para o mercado $j$, no período 2 ;

$V i j=$ valor monetário das exportações da mercadoria $i$ (mel natural) do país em foco para o mercado $j$, no período 1 ;

$V^{\prime} i j$ - Vij = crescimento efetivo do valor das exportações de mel natural do país em foco para o mercado $j$;

$r=$ percentagem de crescimento do valor das exportações mundiais de mel natural do período 1 para o período 2 .

O cálculo do CMS foi realizado para o período de 2000 a 2011, analisando-se os oito principais exportadores, que representam $68 \%$ das exportações mundiais. Foi possível verificar o efeito do crescimento do mercado mundial de mel natural, o efeito do destino das exportações e o efeito da competitividade do mercado mundial de mel natural. no período, tendo o fator pauta sido excluído por se tratar de um único produto.

Partindo desse pressuposto, calculou-se o CMS, sendo selecionado o período entre 2000 e 2011, quando foi observado significativo aumento das exportações de mel natural, em comparação com as da década anterior, e analisados os principais exportadores mundiais: China, Argentina, México, Alemanha, Canadá, Hungria, Espanha e Brasil (Tabela 1).

\section{Índice de vantagem comparativa revelada (IVCR)}

A principal definição do IVCR foi conceituada por Balassa (1965), citado por Fajnzylber et al. (1993), partindo do pressuposto de que o comércio mundial, entre as diferentes nações, ajusta-se conforme as suas vantagens comparativas.
O IVCR mede a estrutura das exportações, considerando, simultaneamente, o desempenho das exportações de um dado produto e o desempenho comercial do país no mercado mundial. Assim, as vantagens comparativas podem ser utilizadas para selecionar os produtos com ganho potencial de comércio. Para o seu cálculo foi utilizada a seguinte expressão matemática (Oliveira, 2005; Pais et al., 2008):

$I V C R_{j}=\frac{\left(X_{i j} / X_{i}\right)}{\left(X_{w j} / X_{w}\right)}$

em que:

$X_{i j}=$ valor das exportações brasileiras de mel natural;

$X_{i}=$ valor total das exportações brasileiras;

$X_{w j}=$ valor total das exportações mundiais de mel natural;

$X_{w}=$ valor total das exportações mundiais;

$i=$ exportações brasileiras;

$w=$ exportações mundiais; $\mathrm{e}$

$j=$ mel natural.

O IVCR foi qualificado conforme critérios apresentados por Pais et al. (2008), sendo:

(a) IVCR $\mathrm{j}>1$ = o país apresenta vantagem comparativa revelada para as exportações de mel natural; e

(b) IVCR j < 1 = o país apresenta desvantagem comparativa revelada para as exportações de mel natural.

\section{RESULTADOS E DISCUSSÕES}

\section{Constant Market Share (CMS)}

O efeito crescimento do comércio mundial representa o crescimento observado, se as exportações do país analisado evoluíram na mesma taxa do crescimento das exportações mundiais. Os principais países exportadores de mel natural apresentaram percentuais positivos no fator crescimento (Tabela 1). O Brasil obteve o menor valor $(1,93 \%)$, seguido pela Espanha $(95,59 \%)$, Hungria $(168,19 \%)$ e Alemanha (182,98\%), enquanto o México, a Argentina e a China apresentaram valores de 305,47, 316,21 e $364,42 \%$, respectivamente. Já o Canadá foi o país mais expressivo, com 706,50\%. De modo geral, os resultados desse efeito comprovam a existência de um crescimento mundial do comércio de mel natural.

$\mathrm{O}$ fator destino forneceu valores percentuais negativos (Tabela 1), com o menor e mais próximo do positivo, obtido pelo Brasil (1,67\%), seguido pela Espanha $(81,95 \%)$, Hungria $(145,63 \%)$ e Alemanha $(159,57 \%)$. Os demais valores foram superiores a $200 \%$, como o do México $(255,34 \%)$, o da Argentina $(266,29 \%)$ e o da China $(295,80 \%)$. O Canadá apresentou o valor expressivo de $598,90 \%$. 
Esse efeito das exportações representa os ganhos (ou perdas) em termos de percentual de crescimento, levando-se em consideração se o país exporta para mercados que crescem a taxas superiores (ou inferiores) àquelas observadas para todos os países. De acordo com Machado et al. (2006) e Grams et al. (2013), o efeito destino das exportações será positivo se um determinado país concentrar as suas exportações em mercados que experimentaram maior dinamismo no período analisado, ao passo que será negativo se concentrado em regiões mais estagnadas.

Neste estudo, os valores negativos (Tabela 1) representaram exportações concentradas para mercados com taxas de crescimento inferiores à média observada para todos os países. O menor índice de efeito destino (Tabela 1) obtido pelo Brasil $(1,67 \%)$ possibilitou inferir que as suas exportações estão crescendo a taxas maiores que a média do mercado mundial, ou seja, o País concentrou-se em mercados com maior dinamismo, ao passo que os demais países concentraram suas exportações para mercados menos dinâmicos.

Considera-se que o efeito competitividade seja reflexo das melhorias nos preços, da qualidade do produto, da redução de custos de produção, ou das condições de investimentos. A competitividade pode ser observada como um efeito de oferta, pois depende da mudança da eficiência relativa dos países no mercado mundial.

No fator competitividade, o Brasil apresentou o maior percentual (Tabela 1), com 99,74\%, seguido pela Espanha $(86,36 \%)$, Hungria $(77,43 \%)$ e Alemanha $(76,59 \%)$. AArgentina, a Espanha e o México tiveram efeito competitividade próximo a $50 \%$, ao passo que o Canadá apresentou percentual negativo $(-7,60 \%)$.

O fracasso ou o sucesso do país no comércio internacional é atribuído ao fator residual. Assim, quando um país não mantém a sua parcela do mercado mundial, a competitividade torna-se negativa, o que indica o fracasso do país em manter sua participação constante. Esse efeito mostra que os importadores tendem a substituir o consumo das commodities, cujos preços se elevaram, pelo consumo daquelas com menores preços relativos (Grams et al., 2013). Esse fato foi verificado com relação ao Canadá (Tabela 1).

O efeito competitividade indica que uma economia é competitiva na produção de determinada commodity, quando consegue, pelo menos, igualar-se aos padrões de eficiência quanto aos recursos e à qualidade (Grams et al., 2013). Dessa forma, os resultados (Tabela 1) indicaram que o Brasil apresentou maior competitividade no mercado mundial de mel natural e padrões de eficiência e utilização de recursos semelhantes aos vigentes no mundo.

O Brasil expressa a evolução da sua participação no mercado mundial no modelo de competitividade estudado. Segundo Pasin et al. (2012), de 2001 a 2003, as exportações brasileiras iniciaram um súbito crescimento, com oscilações em alguns anos, mas chegando a 2011 em quinto lugar no ranking dos maiores exportadores mundiais.

O efeito competitividade brasileira é decorrente de fatores endógenos, determinados pela gestão dos custos, pela qualidade e pelo preço e também recebeu influências de tecnologias de produção, incentivos, marketing, estabilidade econômica, desvalorização cambial, além da escassez do produto no início da década de 2001. Zandonadi \& Silva (2005) ainda acrescentam que o Brasil está tendo oportunidade de competir com outros países no mercado externo de mel, graças à biodiversidade da flora, ao clima favorável, à rusticidade das abelhas, assim como à enorme disponibilidade de mão de obra e tecnologia acessível.

\section{Índice de vantagem comparativa revelada (IVCR)}

O IVCR aplicado neste estudo resultou no valor de 1,65 , que confirma a competitividade das exportações brasileiras de mel natural. Como meio de qualificá-lo, foi utilizada a classificação fornecida por Pais et al. (2008).

Tabela 1: Participação das fontes de crescimento das exportações de mel natural, de 2000 a 2011

\begin{tabular}{lcccc}
\hline \multirow{2}{*}{ País } & Crescimento & Destino & Competitividade \\
\cline { 2 - 4 } & & & Total & \\
\hline Canadá & 706,50 & $-598,90$ & $-7,60$ & 31,37 \\
China & 364,42 & $-295,80$ & 50,08 & 100 \\
Argentina & 316,21 & $-266,29$ & 49,86 & 100 \\
México & 305,47 & $-255,34$ & 76,59 & 100 \\
Alemanha & 182,98 & $-159,57$ & 77,43 \\
Hungria & 168,19 & $-145,63$ & 86,36 \\
Espanha & 95,59 & $-81,95$ & 90 & 100 \\
Brasil & 1,93 & $-1,67$ & 99,74
\end{tabular}

Fonte: Dados adaptados de Uncomtrade (2013). 
O principal aspecto para o aumento da competitividade do mel brasileiro foi a organização do setor apícola, por meio de cooperativas e associações, além do apoio de entidades que possibilitaram o acesso a linhas de créditos e financiamentos, assistência técnica e capacitação dos apicultores. Outros fatores, como a emissão de certificações do mel brasileiro para comprovar a qualidade do produto, pelo Ministério da Agricultura, Pecuária e Abastecimento (MAPA) é feita por meio do serviço de Inspeção Federal (SIF) e de outros órgãos, também têm contribuído para garantir o seu posicionamento no mercado internacional.

A competitividade do mel brasileiro é devida à demanda dos principais mercados consumidores mundiais, que buscam um produto com ausência de resíduos e com padrão de qualidade, no que diz respeito à composição química, ao aroma e ao sabor (Sebrae, 2006). Esses fatores têm contribuído para o crescimento da apicultura no Brasil e, consequentemente, para o aumento de sua participação no mercado internacional.

\section{CONCLUSÕES}

As exportações de mel natural brasileiro são competitivas no mercado internacional estudado, com base nos indicadores de competitividade, constant market share e índice de vantangens comparativa revelada. Analisados pelo critério de desempenho, os resultados mostram que o destino das exportações e a competitividade representam uma posição considerada significante no mercado mundial, pois evidencia que o Brasil exporta para países que apresentam dinâmica no mercado exterior e apresenta competitividade no mercado mundial de mel natural e padrões de eficiência e de utilização de recursos semelhantes aos vigentes no mundo.

Conclui-se que as condições de mercado, proporcionadas pelo aumento na demanda mundial de mel natural, e os custos operacionais, bem como a abundância de fatores de produção, favoráveis ao desenvolvimento da apicultura, são determinantes para o aumento da produção e para a ampliação das exportações brasileiras.

\section{REFERÊNCIAS}

ABEMEL (2013) Associação Brasileira dos Exportadores de Mel. Disponível em: <http://abemel.com.br/portal/>. Acessado em: 05 de junho de 2013.

Alice Web (2013) Sistema de Análise das Informações de Comercio Exterior. Disponível em: <http://aliceweb.desenvolvimento.gov.br/>. Acessado em: 10 de junho de 2013.

Fajnzylber O, Sarti F \& Leal JPG (1993) Estudo da competitividade da indústria brasileira: sistema de indicadores da competitividade. Campinas, IE/FECAMP. 57p.

FAO (2013) Organização das Nações Unidas para Agricultura e Alimentação. Brindging the gap- FAO's programme for gender equality in agriculture and rural development. Disponível em: <ftp://ftp.fao.org/docrep/fao/012/i1243e/i1243e00.pdf>. Acessado em: 20 de dezembro de 2013.
Ferraz JC, Kupfer D \& Haguenauer L (1995) Made in Brazil: desafios competitivos para a indústria brasileira. Rio de Janeiro, Campus. 386p.

Grams JC, Cypriano LA, Coronel DA \& Martins RS (2013) Competitividade das exportações da indústria automobilística brasileira: Uma análise Constant market Share. Desenvolvimento em Questão, 11:247-270.

Horta MHTT (1983) Fontes de crescimento das exportações brasileiras na década de 70. Pesquisa e Planejamento Econômico, 13:507-542.

IBGE - Instituto Brasileiro de Geografia e Estatística (2012) Produção da Pecuária Municipal. Disponível em: <http:// www.ibge.gov.br>. Acessado em: 20 de outubro de 2013.

Machado LVN, Amin MM, Carvalho FMA \& Santana AC (2006) Análise do desempenho das exportações brasileiras de carne bovina: uma aplicação do método Constant Market Share, 19952003. Revista de Economia e Agronegócio, 4:195-218.

Oliveira PB (2005) Competitividade e saldos comerciais da indústria agroalimentar no Brasil. Dissertação de Mestrado. Universidade Federal de Uberlândia, Uberlândia. 167p.

Pais OS, Gomes MFM \& Coronel DA (2008) Análise da competitividade das exportações brasileiras de minério de ferro, de 2000 a 2008. Revista de Administração Mackenzie, 13:121-145

Pasin LEV, Tereso MJA \& Barreto LMRC (2012) Análise da produção e comercialização de mel natural no Brasil no período de 1999 a 2010. Agroalimentária, 18:29-42.

Paula J (2008) Mel do Brasil: as exportações brasileiras de mel no período 2000/2006 e o papel do Sebrae. Brasília, SEBRAE. $99 \mathrm{p}$.

Rangel R (2011) Mel brasileiro conquista mercado externo. Inovação em pauta. Disponível em: <http://www.finep.gov.br/imprensa/ revista/edicao10/inovacao_em_pauta_10_apicultura. pdf >. Acessado em: 10 de novembro de 2013.

Richardson JD (1971) Some sensitivity tests for a "constantmarket-shares" analysis of export growth. The Review of Economics and Statistics, 53:300-304.

SEBRAE - Serviço Brasileiro de Apoio às Micro e Pequenas Empresas (2009) Manual de segurança e qualidade para apicultura. Brasília, SEBRAE/NA. 88p.

SEBRAE - Serviço Brasileiro de Apoio às Micro e Pequenas Empresas (2006) Desafios da apicultura brasileira. Revista SEBRAE Agronegócios, 3:01-64.

Sommer PGO (1998) Desenvolvimento da apicultura brasileira. In: Congresso Brasileiro de Apicultura, Salvador. Anais, UFBA/ SBB. p.173.

Souza DC (2006) ADRs - Os agentes da nova apicultura no Brasil. Revista SEBRAE Agronegócios, 3:46-47.

Uncomtrade (2013) United Nations Commodity Trade Statistics Database. Disponível em: <http://comtrade.un.org/db/ default.aspx>. Acessado em: 05 de junho de 2013.

Valverde SR, Soares NS \& Silva ML (2006) Desempenho das exportações brasileiras de celulose. Revista Árvore, 30:1017-1023.

Zandonadi DA \& Silva OM (2005) Análise da competitividade do Brasil no mercado internacional de mel. In: Congresso da Sociedade Brasileira de Economia e Sociologia Rural, Ribeirão Preto. Anais, SOBER. p.76.

Zandonadi DA \& Silva OM (2006) Competitividade das exportações brasileiras de mel. Revista Econômica do Nordeste, 37:3753. 